\section{Transfusion Medicine and Hemotherapy}

\title{
Developmental Strategies of Novel Anticoagulants*
}

\author{
Bernd Pötzsch Jens Müller Jutta-Maria Rox \\ Institut für Experimentelle Hämatologie und Transfusionsmedizin, Universitätsklinikum Bonn, Bonn, Deutschland
}

\author{
Key Words \\ New anticoagulants - Bivalirudin - Idraparinux - NAPc2 . \\ Factor IXa aptamer · Drug design
}

\section{Summary}

This minireview discusses developmental approaches of novel anticoagulants. The technology of drug design has been successfully used to modify established anticoagulants in a way that the pharmacological activity and safety is improved. This is exemplified on the development of bivalirudin, a hirudin derivative, and of idraparinux, a synthetic heparin derived from fondaparinux. A second approach includes characterization of human or nonhuman anticoagulant proteins and their subsequent production using recombinant technologies. As an example the nematode anticoagulant protein NAPc2 that was originally isolated from the canine hookworm Ancylostoma caninum is discussed. Finally, the development of aptamers that inhibit activated factor IX is discussed. This example indicates that employment of a novel technology can extend the anticoagulant armamentarium.

\section{Introduction}

There are at least three general approaches for the development of novel anticoagulants. One approach is to modify established anticoagulants through structure-based drug design

*Dedicated to Prof. Dr. Peter Hanfland, Bonn, on the occasion of his 65th birthday.
Schlüsselwörter

Neue Antikoagulanzien - Bivalirudin - Idraparinux . NAPc2 - Faktor-IX-Aptamer · Medikamentendesign

\section{Zusammenfassung}

Neue Antikoagulanzien können mit verschiedenen methodischen Ansätzen entwickelt werden. Die Techniken des Medikamentendesigns ermöglichen es, das Wirkungsprofil von bereits etablierten Antikoagulanzien gezielt zu verändern und dadurch zu optimieren. Dieses Vorgehen wird am Beispiel des Hirudinabkömmlings Bivalirudin und des synthetisch hergestellten lang wirksamen Heparins Idraparinux dargestellt. Eine andere Möglichkeit, neue Antikoagulanzien für den therapeutischen Einsatz verfügbar zu machen, besteht darin, natürlicherweise vorkommende und antikoagulatorisch wirkende Proteine menschlichen oder tierischen Ursprungs zu charakterisieren und rekombinant herzustellen. Das antikoagulatorisch wirkende Nematodenprotein NAPc2 wird als ein Beispiel für diesen Ansatz besprochen. Die abschließend dargestellten Faktor-IXa-Aptamere zeigen, dass durch den Einsatz einer neuen Technologie neue Ansatzpunkte für eine antikoagulatorische Therapie realisiert werden können.

in order to improve their anticoagulant features. A second approach is to characterize human and non-human anticoagulant proteins and to produce these anticoagulants by recombinant DNA technologies. A third approach is to develop new drugs that address anticoagulant mechanisms which have not been used so far as targets for anticoagulant drugs. The hirudin derivative bivalirudin and the synthetic heparin idraparinux are examples for the development of new anticoagulants by structure-based drug design.

\begin{tabular}{ll}
\hline KARGER & ( ) 2006 S. Karger GmbH, Freiburg \\
Fax +497614520714 & Accessible online at: \\
$\begin{array}{l}\text { E-mail Information@Karger.de } \\
\text { www.karger.com }\end{array}$ & www.karger.com/tmh \\
&
\end{tabular}

Prof. Dr. med. Bernd Pötzsch

Institut für Experimentelle Hämatologie und Transfusionsmedizin

Universitätsklinikum Bonn

Sigmund-Freud-Straße 25, 53105 Bonn, Germany

Tel. +49 228 287-6745, Fax -9090

E-mail bernd.poetzsch@ukb.uni-bonn.de 


\section{Bivalirudin: a 'Designer' Hirudin}

Hirudin is a directly acting thrombin inhibitor that was originally isolated from the salivary glands of the medical leech Hirudo medicinalis and is now available in recombinant form [1]. Hirudin is a 65 -amino acid polypeptide that binds and inhibits thrombin in a bivalent fashion. Its globular amino-terminal domain interacts with the active site of thrombin, whereas its anionic carboxy-terminal tail binds to exosite 1 on thrombin, the substrate recognition site. The hirudin/thrombin complex is essentially irreversible, which is a potential drawback because there is no specific antidote.

The results of various clinical studies demonstrate that hirudin is at least as effective as heparin in treating patients with acute coronary syndromes and is more effective than low-molecularweight heparin and unfractionated heparin for the prevention of venous thrombosis in patients undergoing elective hip arthroplasty [2,3]. A major drawback of hirudin, however, is its narrow therapeutic window and the associated bleeding risk. The narrow therapeutic window is caused by the renal way of elimination and the missing antidote.

To overcome these limitations of hirudin without loosing its advantages, bivalirudin has been designed. Within the bivalirudin molecule the amino-terminal D-Phe-Pro-Arg-Pro sequence of hirudin, which binds to the active site of thrombin, is connected via four Gly residues to a carboxy-terminal dodecapeptide that interacts with exosite 1 on thrombin (fig. 1) [4]. Like hirudin, bivalirudin forms a 1:1 stoichiometric complex with thrombin. However, once bound, thrombin cleaves the Pro-Arg bond within the amino-terminal end of bivalirudin, thereby allowing the recovery of thrombin activity [5]. It has been proposed that this phenomenon may render bivalirudin safer than hirudin. Bivalirudin has a plasma halflife of $25 \mathrm{~min}$ after intravenous injection, and only a fraction is excreted via the kidneys [6,7].

Bivalirudin has been evaluated in patients undergoing percutaneous coronary interventions and as an adjunct to streptokinase therapy in patients with acute myocardial infarction. In the setting of percutaneous coronary intervention, bivalirudin appears to be at least as effective as heparin and produces less bleeding. More interestingly, it has been shown that for patients with a low-to-moderate risk of bleeding who are undergoing percutaneous coronary interventions without receiving an adjunctive GPIIb/IIIa antagonist, bivalirudin may be a better choice than heparin [8].

\section{Idraparinux: Design of a Long-Acting Heparin}

The 'relatively' short plasma half-life of low-molecular-weight heparins limit their use as an anticoagulant in patients requiring extended or long-term anticoagulant treatment. To overcome this limitation idraparinux, a long-acting synthetic heparin, was developed. Idraparinux is a highly sulfated deriva-

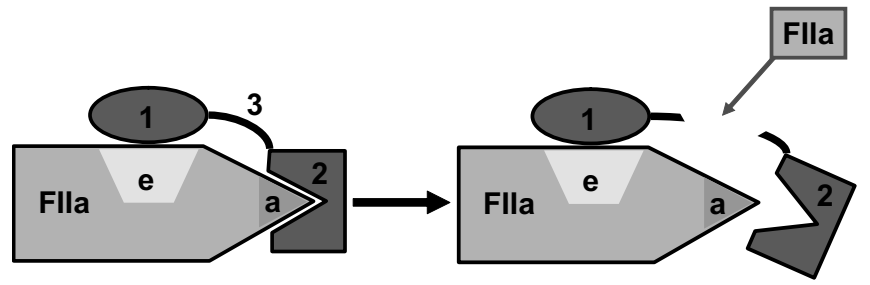

Fig. 1. Mechanism of action of bivalirudin. Bivalirudin consists of 3 distinct domains: an acitve catalytic site domain (1), a carboxyl terminal region (2), and a linking region (3). In a first step bivalirudin inhibits thrombin (FIIa) activity by binding to the active catalytic site (a) and to the substrate recognition site (s). Thereafter thrombin slowly cleaves the Arg3-Pro4 bond in the active site domain and thrombin partially retains its catalytic activity. The remaining carboxyl terminal domain of bivalirudin is then displaced in a competitive manner.

tive of fondaparinux that binds antithrombin with such high affinity that its plasma half-life of $130 \mathrm{~h}$ is similar to that of antithrombin [9]. Because of its long half-life, idraparinux can be given subcutaneously on a once-weekly basis.

In a dose-finding phase II trial idraparinux was compared with warfarin in 659 patients with proximal deep vein thrombosis (DVT). After 5-7 days of initial treatment with enoxaparin, patients were randomized to receive once-weekly subcutaneous doses of idraparinux $(2.5,5,7.5$, or $10 \mathrm{mg})$ or warfarin for 12 weeks [10]. The primary endpoint, changes in compression ultrasound and perfusion lung scan findings, was similar in all idraparinux groups. There was a clear dose response for major bleeding in patients who had received idraparinux, with an unacceptably high frequency in those receiving the $10 \mathrm{mg}$ dose. Two patients, both of whom received $5 \mathrm{mg}$ idraparinux once weekly, experienced a fatal bleeding incident. Patients who received the lowest dose of idraparinux had less bleeding than those randomized to receive warfarin $(p=0.029)$. Based on these results, a once-weekly $2.5 \mathrm{mg}$ dose of idraparinux will be used in ongoing phase III clinical trials where idraparinux is being compared with warfarin for treatment of patients with DVT or pulmonary embolism and for prevention of cardioembolic events in patients with atrial fibrillation [11].

\section{Human and Non-Human Biologics as New Anticoagulants}

Blood-feeding animals are good candidates to search for new anticoagulant proteins and peptides. The most prominent anticoagulant that was developed following such an approach is hirudin. Another example is the nematode anticoagulant protein c2 (NAPc2) that was originally isolated from the canine hookworm Ancylostoma caninum [12]. The hookworm is an intestinal parasite of humans and animals. In the small intestine hook worms attach to the intestinal wall and suck blood (fig. 2). To avoid blood clotting the worm adds NAPc2 to the 

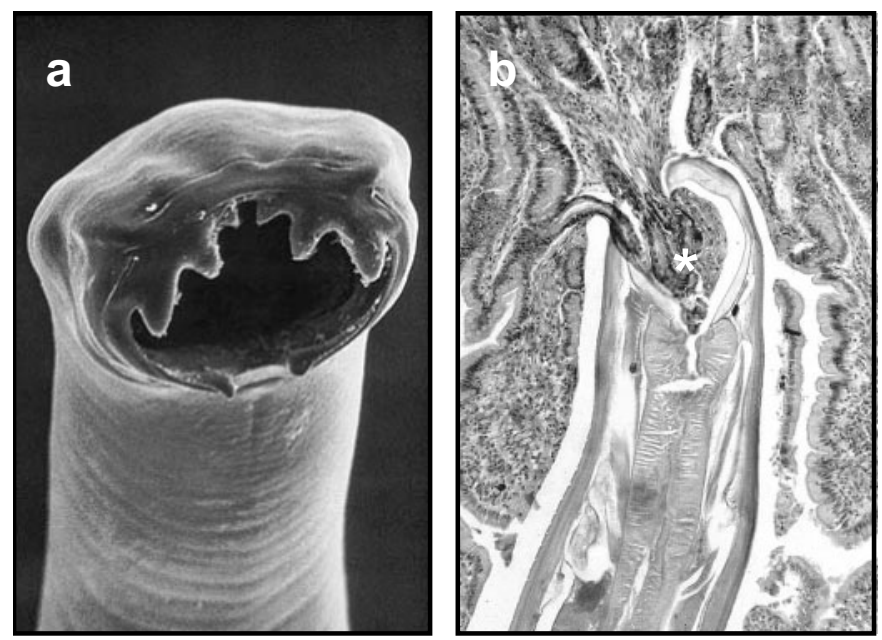

Fig. 2. The hookworm Ancylostoma caninum. a The hookworm Ancylostoma caninum is a blood feeding parasite. $\mathbf{b}$ The worms attach to the intestinal wall and suck blood.

Fig. 3. Mechanism of action of nematode anticoagulant protein c2 (NAPc2). The hookworm anticoagulant NAPc2 is a potent inhibitor of the TF/FVIIa complex. NAPc2 binds with high affinity to a non-catalytic site of FX or FXa. The re-

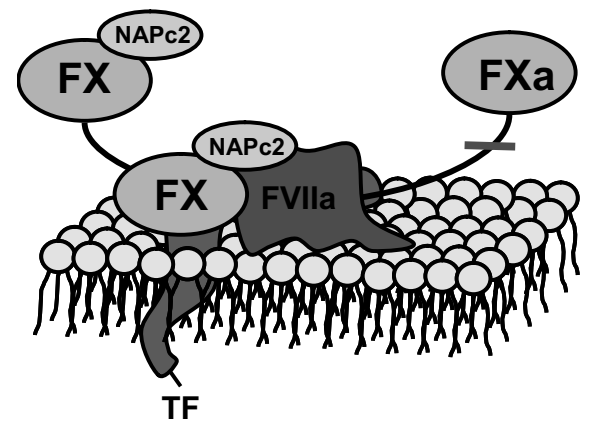
sulting FXa-NAPc2complex inhibits the catalytic activity of FVIIa within the TF-FVIIacomplex. sucked blood. NAPc2 is a 85-amino acid polypeptide, and a recombinant version of NAPc2 can be expressed in yeast. NAPc2 binds to a non-catalytic site on factor X (FX) or activated factor $\mathrm{X}(\mathrm{FXa})$. Once bound to FXa, the NAPc2FX/FXa-complex inhibits factor VIIa (FVIIa) bound to tissue factor (TF) (fig. 3). Because it binds to FX with high affinity, NAPc2 has a half-life of approximately $50 \mathrm{~h}$ after subcutaneous injection.

NAPc2 has been tested for the prevention of postoperative DVT in a phase II dose finding study [13]. A total of 293 patients undergoing elective knee arthroplasty were given subcutaneous NAPc2 on the day of surgery and every 2nd day thereafter to a maximum of four doses [13]. The best results were observed with an NAPc2 dose of $3 \mu \mathrm{g} / \mathrm{kg}$ administered $1 \mathrm{~h}$ after surgery. With this dose, the overall rate of venographically detected DVT in the operated leg was $12 \%$ while the rate of proximal DVT was $1 \%$. Major bleeding occurred in $2 \%$ of these patients. When compared with historical control subjects, the efficacy and safety of NAPc2 are similar to those

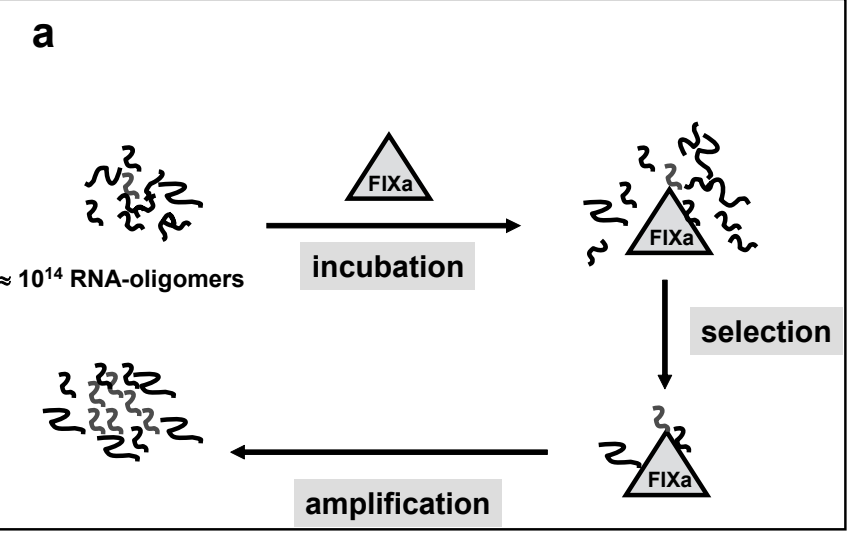

b

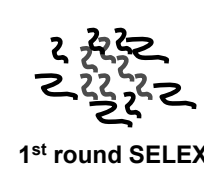
preselected RNAs
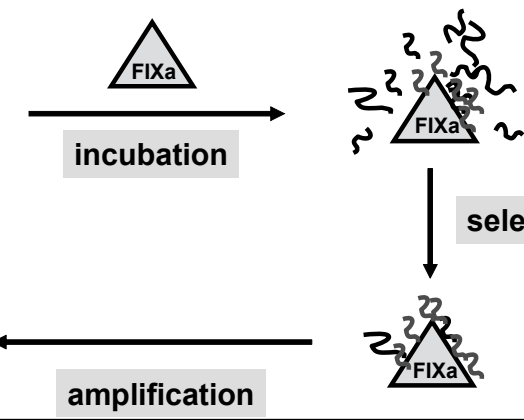

selection

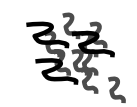

Fig. 4. Selection of aptamers. Aptamers are selected by systematic evolution of ligands by exponential enrichment (SELEX). a In the first round of SELEX the target of interest is incubated with a random sequence library. During incubation a small fraction of individual sequences interacts with FIXa. During the selection step sequences that do not interact with the target are removed and the population of sequences bound to the target is isolated and amplified. b The resulting enriched library is used for the next SELEX cycle.

of low-molecular-weight heparin. However, prospective randomized trials are needed to confirm these findings.

Since it has been shown that the expression of TF plays a crucial role in the pathogenesis of arterial thrombosis, current trials focus on the use of NAPc2 in patients with unstable angina or non-ST-elevation myocardial infarction and in those undergoing percutaneous coronary interventions. For each of these indications, NAPc2 is being compared with placebo as an adjunct to antiplatelet therapy (with aspirin, clopidogrel, and, in some cases, a glycoprotein (GP) IIb/IIIa antagonist and an antithrombin (either heparin or low-molecular-weight heparin)) [14].

\section{Factor IXa Aptamer: a New Anticoagulant Tool}

The aptamer technology has been employed for the development of a therapeutic anticoagulant that targets activated factor IXa (FIXa). FIXa is the active serine protease within the tenase complex that catalyses conversion of FX into its active 


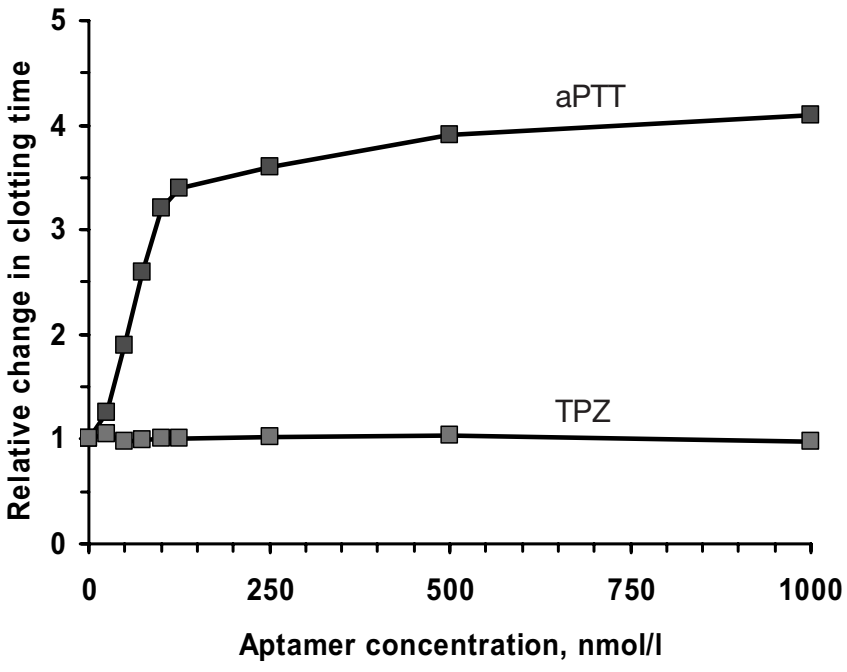

Fig. 5. In vitro anticoagulant function of the anti-FIXa aptamer 9.3. Addition of the anti-FIXa aptamer to normal human plasma induces a concentration-dependent prolongation of the activated partial thromboplastin time (aPTT), whereas there was no effect on the thromboplastin time (TPZ) [16].

form. The tenase complex plays an essential role in the propagation of the hemostatic process. This makes it to an attractive target for the development of a new anticoagulant.

The ability of nucleic acids to fold into a variety of different structures is the basis of the aptamer technology. The term 'aptamer' is derived from the latin word 'aptus' that means 'to fit' and combines 'aptus' with 'oligomers'. Aptamers are selected from random sequence libraries by an iterative process of in vitro selection and amplification originally described in a paper by Tuerk and Gold [15]. This process is called SELEX (systematic evolution of ligands by exponential enrichment). In the first step of the SELEX procedure the target of interest, here FIXa, is incubated with a random sequence library containing $\approx 10^{14}$ RNA oligomers (fig. $4 \mathrm{a}$ ). During this step a very small fraction of individual sequences tends to interact with FIXa, and these sequences are separated from the rest of the library by immobilization of the FIXa aptamer complexes on nitrocellulose membranes or through biotin-avidine interactions. Sequences that do not interact with the target on the solid support are removed by washing. The population of sequences bound to the target is isolated and amplified to obtain an enriched library to be used for the next selection/amplification cycle (fig. 4b). Starting from a $10^{14}$-fold combinatorial li-

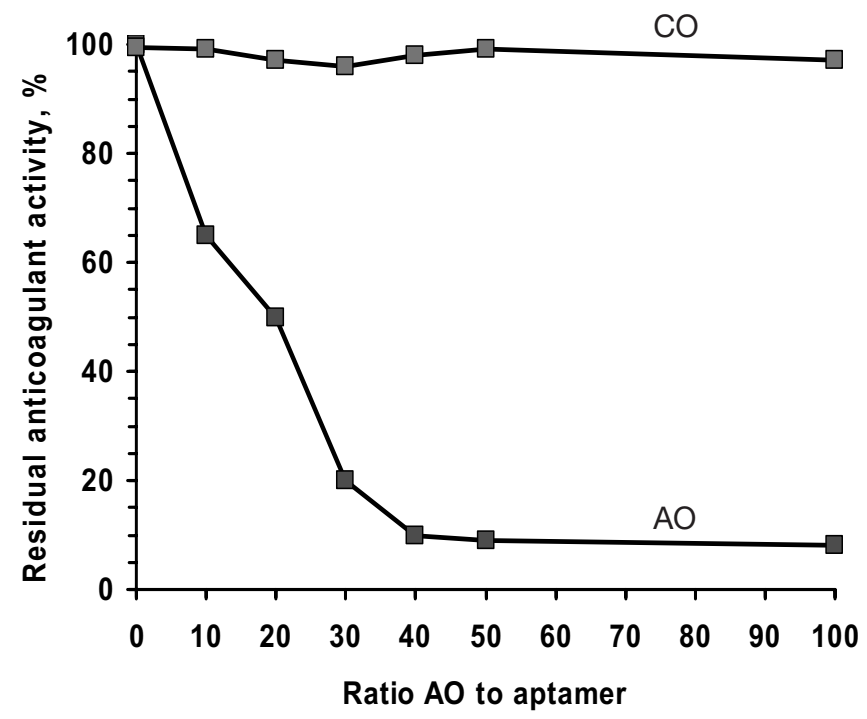

Fig. 6. Antidote aptamer. Addition of the antidote oligonucleotide (AO) to normal human plasma neutralizes the anticoagulant effect of the FIXa aptamer whereas the control oligonucleotide (CO) was not effective [16].

brary of 80-nucleotide RNAs, Rusconi et al. [16] selected FIXa aptamers. By comparing the effective sequences, the authors generated a modified RNA aptamer, 31 nucleotides in length and stabilized against both exonuclease and endonuclease degradation. This aptamer prolongs the clotting time of normal human plasma in a dose-dependent manner as measured in activated partial thromboplastin assays, but had no effect in prothrombin assays, demonstrating that the aptamer specifically inhibits the FIXa pathway in plasma (fig. 5).

Bleeding is a serious side effect of all anticoagulants. As a consequence, the availability of a rapidly acting antidote will enhance the safety and facilitate the medical use of an anticoagulant. Using again the aptamer technology, Rusconi et al. [16] generate a matching antidote against the FIXa aptamer. This antidote aptamer rapidly reverses the anticoagulant activity of the FIXa aptamer as tested in human plasma.

Preclinical pharmacology studies have shown that the FIXa aptamer can effectively inhibit thrombus formation in an animal vascular injury model and can replace heparin in an animal cardiopulmonary bypass model [17]. Despite these promising data, further clinical testing of these aptamers is limited by the high costs of chemical manufacturing of aptamers.

\section{References}

1 Wallis RB: Hirudins: from leeches to man. Semin Thromb Hemost 1996;22:185-196.

- 2 Eriksson BI, Wille-Jorgensen P, Kalebo P, Mouret P, Rosencher N, Bosch P, Baur M, Ekman S, Bach D, Lindbratt S, Close P: A comparison of recombinant hirudin with a low-molecular-weight heparin to prevent thromboembolic complications after total hip replacement. N Engl J Med 1997;337: 1329-1335.
3 Eriksson BI, Ekman S, Lindbratt S, Baur M, Bach D, Torholm C, Kalebo P, Close P: Prevention of thromboembolism with use of recombinant hirudin: results of a double-blind, multicenter trial comparing the efficacy of desirudin (Revasc) with that of unfractionated heparin in patients having a total hip replacement. J Bone Joint Surg Am 1997; 79:326-333.
4 Witting JI, Bourdon P, Maraganore JM, Fenton JW 2nd: Hirulog-1 and -B2 thrombin specificity. Biochem J 1992;287:663-664.

5 Witting JI, Bourdon P, Brezniak DV, Maraganore JM, Fenton JW 2nd: Thrombin-specific inhibition by and slow cleavage of hirulog-1. Biochem J 1992; 283:737-743. 
6 Fox I, Dawson A, Loynds P, Eisner J, Findlen K, Levin E, Hanson D, Mant T, Wagner J, Maraganore $\mathrm{J}$ : Anticoagulant activity of hirulog, a direct acting thrombin inhibitor, in humans. Thromb Haemost 1993;69:157-163.

7 Robson R: The use of bivalirudin in patients with renal impairment. J Invasive Cardiol 2000;12: $33 \mathrm{~F}-36 \mathrm{~F}$.

8 Bittl JA, Strony J, Brinker JA, Ahmed WH, Meckel CR, Chaitman BR, Maraganore J, Deutsch E, Adelman B: Treatment with bivalirudin (hirulog) as compared with heparin during coronary angioplasty for unstable or post infarction angina: Hirulog Angioplasty Study Investigators. N Engl J Med 1995;333:764-769.

-9 Herbert JM, Herault JP, Bernat A, van Amsterdam RG, Lormeau JC, Petitou M, van Boeckel C, Hoffmann P, Meuleman DG: Biochemical and pharmacological properties of SANORG 34006, a potent and long-acting synthetic pentasaccharide. Blood 1998;91:4197-4205.

10 Persist Investigators: A novel long-acting synthetic factor Xa inhibitor (SanOrg34006) to replace warfarin for secondary prevention in deep vein thrombosis: a phase II evaluation. J Thromb Haemost 2004;2:47-53.

11 Weitz JI, Bates SM: New anticoagulants. J Thromb Haemost 2005;3:1843-1853.

12 Cappello M, Vlasuk GP, Bergum PW, Huang S, Hotez PJ: Ancylostoma caninum anticoagulant peptide: a hookworm-derived inhibitor of human coagulation factor Xa. Proc Natl Acad Sci U S A 1995;92:6152-6156.

13 Lee A, Agnelli G, Buller H, Ginsberg J, Heit J, Rote W, Vlasuk G, Costantini L, Julian J, Comp P, van Der Meer J, Piovella F, Raskob G, Gent M: Dose-response study of recombinant factor VIIa/tissue factor inhibitor recombinant nematode anticoagulant protein $\mathrm{c} 2$ in prevention of postoperative venous thromboembolism in patients undergoing total knee replacement. Circulation 2001;104: 74-78.

14 Moons AH, Peters RJ, Bijsterveld NR, Piek JJ, Prins MH, Vlasuk GP, Rote WE, Buller HR: Recombinant nematode anticoagulant protein $\mathrm{c} 2$, an inhibitor of the tissue factor/factor VIIa complex, in patients undergoing elective coronary angioplasty. J Am Coll Cardiol 2003;41:2147-2153.

15 Tuerk C, Gold L: Systematic evolution of ligands by exponential enrichment: RNA ligands to bacteriophage T4 DNA polymerase. Science 1990;249: 505-510.

16 Rusconi CP, Scardino E, Layzer J, Pitoc GA, Ortel TL, Monroe D, Sullenger BA: RNA aptamers as reversible antagonists of coagulation factor IXa. Nature 2002;419:90-94.

17 Becker RC, Rusconi C, Sullenger B: Nucleic acid aptamers in therapeutic anticoagulation - technology, development and clinical application. Thromb Haemost 2005;93:1014-1020. 